Review

\title{
Assessing the Functional Status of Older Cancer Patients in an Ambulatory Care Visit
}

\author{
Janine Overcash \\ College of Nursing, the Ohio State University, 1585 Neil Avenue, Columbus, OH 43220, USA; \\ E-Mail: Overcash.1@osu.edu
}

Academic Editors: Tracey L. Yap and Melissa Batchelor-Murphy

Received: 29 June 2015 / Accepted: 10 September 2015 / Published: 18 September 2015

\begin{abstract}
Functional status assessment is a useful and essential component of the complete history and physical exam of the older patient diagnosed with cancer. Functional status is the ability to conduct activities that are necessary for independence and more executive activities, such as money management, cooking, and transportation. Assessment of functional status creates a portal into interpreting the health of in older persons. Understanding limitations and physical abilities can help in developing cancer treatment strategies, patient/family teaching needs, and in-home services that enhance patient/family care. This article will review the benefits of functional assessment, instruments that can be used during an ambulatory care visit, and interventions that can address potential limitations.
\end{abstract}

Keywords: comprehensive geriatric assessment; functional status; geriatrics

\section{Introduction}

Functional status scores are predictive of falls [1,2], longer hospital stays [3], disease-related symptoms [4], poor tolerance to chemotherapy [5,6], emotional concerns [7], mortality [8], and general health status [9]. People aged 80 years and over are more likely to exhibit poor functional status even in the absence of multiple diagnostic conditions or cognitive disability [10]. Functional impairment at age 70 predicts mortality and institutionalization [11] and is more helpful than chronological age when predicting treatment outcomes [12]. This article will review the benefits of functional assessment, instruments that can be used during an ambulatory care visit and interventions that can address potential limitations. 


\section{Descriptions of Functional Status}

Many providers fail to perform a functional assessment on older patients in clinical practice, despite $42 \%$ of community-dwelling seniors [13] and $63 \%$ of hospitalized elders having functional deficits [14]. In 1991, a classic study found that $66 \%$ of providers failed to address functional limitations even when specifically reported by the patient during an office visit [15]. Currently, functional status assessments are routinely performed in areas such as emergency rooms [16], oncology clinics [17], hemodialysis centers [9] hospitals [18,19], and primary care clinics [20]. Clinical guidelines from the Hartford Institute for Geriatric Nursing [21] and the American Geriatrics Society [22] provide recommendations for assessment and management of functional limitations.

Traditional elements of functional status are bathing, dressing, feeding, transferring, toileting, continence, housekeeping, using a telephone, cooking, transportation, managing money, and the ability to administer medication as prescribed $[23,24]$. Some tasks require predominate cognitive skills such as managing money, self-administering medications, using the telephone, and others require sufficient motor skills such as walking and transferring [25]. The elements of functional status address basic activities necessary to live independently such as bathing, dressing, feeding, transferring, and toileting. Without the ability to conduct these functions, assistance is required to continue to live in the community. Each element of functional assessment has predictors for other limitations, different types of interventions and associated problems.

\subsection{Transportation}

Transportation can be a barrier to healthcare [26-28], a financial hardship [29], and a stressor for caregivers, especially when patients require regular medical attention [30]. Problems such as impairment in functional status, cognitive deterioration, and failing vision are associated with driving cessation [31]. The inability to drive or obtain transportation reduces the ability to live independently. Assessing specifically how patients travel to the grocery store and accomplish errands is important to healthcare management and is a vital aspect of the functional assessment.

\subsection{Bathing and Dressing}

Bathing and dressing are basic tasks that can be difficult, especially if a bathroom is not equipped with handles, raised toilet seats, and other adaptive devices that help reduce slip and fall injuries. Bathrooms tend to be dangerous areas of the house for older people [32] Bathtubs often require a high step over the side of the basin and can have wet, slippery surfaces which can enhance fall risk for people with reduced mobility, poor balance or neuropathies. The inability to bathe independently is a predictor of nursing home placement [33].

\subsection{Preparing Meals}

Physical and mental abilities are required to prepare meals. For physically compromised older patients diagnosed with COPD patients, $88 \%$ required assistance with cooking [34]. Among general community-dwelling elders, $13 \%$ report deficits with cooking [13]. Those with impaired cognitive ability and without caregiver support, using a stove can be dangerous. Using fresh ingredients or non-spoiled 
food can be difficult and reduced sense of smell or vision may restrict the ability to notice if food has spoiled. The ability to prepare meals can be a vital aspect of independent living.

\subsection{Incontinence}

Urinary incontinence is associated with a decline in general functional ability [35], falls [36], and is another prime factor in nursing home placement decisions [37]. A functional status assessment will help determine if incontinence exists, and possible causes. Incontinence is considered a geriatric syndrome, because of multiple confounders which make management difficult [38]. Approximately half of community-dwelling women aged 65 and over report urinary incontinence [39]. Fecal incontience should also be assessed. Fecal incontinence includes rectal leakage in the form of mucus and or stool.

\subsection{Medication Administration at Home}

Patients and caregivers frequently make mistakes when administering medications. The frequency of medication errors occurs up to 59\% among community-dwelling elders [40]. The types of medication errors are associated with patient modification of the dosing orders (41.9\%), faulty administration (31.8\%), and not following clinical advice (21.7\%) [41]. The majority of medication self-administration errors occur in people aged 80 years and over and those who have multiple diagnoses [42].

\subsection{Money Management}

Many seniors who are diagnosed with dementia do not relinquish managing the household finances even after mistakes have occurred [43]. In people aged 60 years and over, 11\% have reported functional difficulty managing money and paying bills [13]. Even mild cognitive impairment can lead to problems managing money [44]. Discussions concerning the designation of another person to manage finances are delicate and difficult.

\subsection{Using a Telephone}

Using a telephone may not be a problem for many; however, poor vision, mental disability, and limited dexterity may reduce ability to operate a phone. Cell phones are largely replacing landlines in the United States and some of the large numbered telephones developed for people with poor vision and reduced dexterity are no longer available. According to the Pew Research Center, 23\% of people aged 65 years and over do not use cell phones [45]. However, the younger old those who are highly educated and seniors of higher socioeconomic status tend to embrace technology. Most seniors over age 65 years do own and use a cell phone. Approximately, 77\% of seniors reported being cell phone users in 2014, which is up from 69\% in 2012 [45]. Understanding if a senior has the ability to call in case of emergency is an important element of the functional status assessment.

\section{Benefits of Functional Assessment}

Functional status assessment is helpful in understanding surgical risk and recovery [46] Older patients who have functional limitations preoperatively tend to have longer hospital stays along with unfavorable surgical outcomes [3], higher rate of mortality [47] and likely to experience readmission to 
acute care facilities [48]. Decisions regarding surgical versus medical management incorporate functional condition in addition to factors associated with general health and life expectancy [49]. Functional status scores along with other geriatric assessment measures can be used to determine surgical risk [50], one-year mortality [51], and changes in cancer treatment, such as intensification, decrease or delay in dose [52].

A functional status assessment provides the impetus for critical discussions among the family/support persons and the healthcare team about driving, living alone, managing money and health management options. Discussions concerning such issues create a great deal of tension among families. Loss of independence motivates transitions from living in a home of many years, to a smaller apartment or assisted living. For some families, nursing and physician clinical recommendations can help ameliorate anger or frustration for an older person who may be losing the ability to live independently.

It is important to remember that not every older person has a functional deficit. Appropriately, 23\% of centenarians reported having no major chronic disease and 18\% having no disability [53]. Many seniors exercise regularly, report high activity levels, and have no problems paying monthly bills [54]. Those aged 65-74 years (79\%) had good or better health compared to those aged 85 years $(67 \%)$ and over who reported good or better health [55].

\section{Evaluating Functional Status}

There are two ways to assess functional status which are self-report and performance evaluation. Many self-report instruments are valid and reliable and are used in clinical practice and research. Self-report instruments are tools equipped with questions the patient answers based on the ability to perform tasks. Performance evaluations are instruments used by nurses and physicians to empirically evaluate activities, such as gait, speed or grip strength.

\subsection{Functional Assessment Cancer Therapy Scales}

The Functional Assessment Cancer Therapy Scales (FACT) are instruments that measure quality of life with a functional assessment domain [56]). Many versions are developed for specific cancer diagnoses (the FACT-G is a general instrument) and the instruments are often used in research. The FACT is a reliable and valid 28-item self-assessment divided into four categories (physical, social/family, emotional, and functional well-being), and the internal consistency score is 0.89 [57]. The FACT-G has age related norms for scoring [58].

\subsection{Short Form-36}

Another quality of life instrument that also addresses a functional domain is the Short Form-36 [59]. Eight health-related concepts are included in the instrument: Physical functioning, social functioning, role limitation due to physical functioning, bodily pain, general health perceptions, vitality and role limitations caused by emotional problems, and mental health. The first four measures of physical health are combined to include a summary score of physical functioning. Generally, the SF-36 is a tool used in research and can help understand the relationship between physical functioning and emotional health. The instrument requires $15 \mathrm{~min}$ to complete. Scores are calculated and transformed to a 1 to 100 scale; with higher scores indicating better health. Reliability of the SF-36 scale has been assessed 
using Cronbach's alpha coefficient with results ranging from 0.78 in general health perceptions to 0.91 in the physical functional domain. Discriminate validity has been demonstrated by the ability to classify subjects with and without other indications of poor health. The SF-36 is that is has age-related norms.

\subsection{The Barthel Activity Index}

The Barthel Activity Index is a scale commonly used in clinical practice to assess rehabilitation changes in stroke patients [60]. The Barthel consists of 10 items and the higher the score, the better the function. Bowel and bladder continence, feeding, grooming, dressing, transferring, toilet use, mobility, stairs, and bathing are the items included on the Barthel Activity Index and are intended to establish the level of independence. The internal consistency reliability for the Modified Barthel Index was 0.90, compared to 0.87 for the original scoring [61].

\subsection{The Activity of Daily Living and Instrumental Activities of Daily Living}

The Activity of Daily Living (ADL) scale is frequently used in clinical practice and part of a comprehensive geriatric assessment (CGA) used in inpatient and outpatient settings [23]. The ADL consists of six items and the instrument prompts the clinician to evaluate each task and determine whether a person is independent. If a person is dependent in any of the tasks, decisions concerning assistance and rehabilitation are then generally explored.

The Instrumental Activities of Daily Living (IADL) [24] addresses more refined activities as compared to the ADL scale. Using the telephone, getting to places beyond walking distance, grocery shopping, laundry, cleaning and housekeeping activities, and managing money are the six domains. The IADL has 11 items and is scored in that the patient earns three points for being able to perform a task without assistant, two points for some assistance, and one point for being completely unable. Dependence is defined by any one task that requires assistance. Validity was addressed using the Physical Self-Maintenance Scale (PSMS), Mental Status Questionnaire (MSQ) [62], Physical Classification (PC), Behavior and Adjustment rating Scale (BA) and all were significantly correlated at 0.1 with the exception of the BA scale. Reliability was established by two participants using the IADL scale on material from an interview (0.85) [24]. Current recommendations are to score IADL the same for men and women [63].

\subsection{Fall Assessment}

Falls are also related to functional status. The IADL tool is a predictor of falls in cancer patients [17] and the ADL tool is also predictive of falls in general geriatric populations [1]. The gold standard for fall screening is the simple question of whether a fall has occurred in the last six months [64]. If the patient has fallen within the last year a "Timed Get-up and Go" Test is performed [65].

\section{Performance Evaluation}

\subsection{The Timed Get Up and Go Test (TGUAT)}

The TGUAGT is performed by asking the person to rise from a straight backed chair and walk 10 feet, turn, return and sit down again. The patient is rated from a score of one (highest risk of fallings) to five 
(lowest risk of falling). The tests will be timed (under $10 \mathrm{~s}$ the patient is freely independent and over $30 \mathrm{~s}$ the patient is dependent on the assistance of others) [65]. The TUAGT [65] considers balance in the ability to rise from a sitting position and ambulate 10 feet and return to a sitting position. The TUAGT has been found to be correlated with falls [66].

\subsection{Grip Strength}

Grip strength is a performance measure that can help determine any possible limitations in mobility. Scores of three successive trials for each hand tested are recorded. The average score of the three trials can be compared to the normative data. From a statistical perspective, scores within two standard deviations of the mean are considered within normal limits. In addition, the individuals' ability to use their hand functionally needs to be considered when interpreting a grip strength performance (Jamar handbook). Cutpoints are available from the manufacturer of the diameter and are specific to right or left hand and gender. Grip strength is associated with walking ability in hospitalized older patients [67]. Grip strength is also associated with poor physical performance in men [68].

\subsection{Gait Speed}

The six-minute walk test (6MWT) is reflective of functional ability [69] and can be considered a vital sign of general health [70]. The 6MWT is reflective of a person who requires total care to someone who is fit and less likely to be hospitalized [71]. Gait speed predicts hospitalizations [72] and mortality [73]. However, in chronic heart failure patients, the 6MWT is not clinical useful or predictive of cardiac function or exercise capacity [74]. Some parameters have been established for the test, use a walkway greater than five meters, asking the person to walk comfortably and use a stop watch for timing.

\section{Management of Functional Status Limitations}

The percentage of community-dwelling elders who recover from loss of function is estimated to be $81 \%$ [75]. Functional status limitations may be temporary and associated with a surgical procedure or as a result of an injury as compared to limitations associated with frailty, terminal illness or from chronic disease. People who are active and considered "fit" have more physical reserve and able to recover functional loss [76]. Recovering functional loss can require occupational/physical therapy, exercise, and regular movement and patients along with clinicians should be vigilant to encourage physical activity.

Determine if the limitations are mentally or physically inspired. Mild cognitive impairment can impinge on driving and handling money [44]. Depression can be assocaited with functional status changes. People who are diagnosed with depression are more likely to report problems with activities of daily living and cognitive changes [77]. The more symptoms of depression, the more functional limitations experienced by the patient [78]. Managing depression will help improve functional abilities [79].

Many older patients experience functional decline during hositalization. In a Taiwanese study, up to $74 \%$ of older people develop functional impairment during a hospital admission and $32 \%$ of those had an impairment six months after discharge [80]. Bedrest is a prime feature in transitioning from no disability to severe disability [81]. It is important to maintain sensory stimulation and regular walking regiemes [82]. Nurses and the entire healthcare team must play a role in the maintenance of functional status. Recognizing 
that a hospitalization can be detrimental to the physical ability of an older person, hospitals must embrace education and promotion of physical function [83]. Offering function-focused care can help perserve functional status while in the hospital [84]. All healthcare team members should be vigulant reguarding medications and potential drug errors which can have an effective on functional status [85].

Trends in functional status scores can help the clinical team make treament decisions. Functional status assessments should be conducted regularly to understand the burden of disability [75]. A single functional assessment can be helpful, but does not provide the comprehensive understanding of capability. Treatments and progression of disease are reflected in functional status scores and can help with decisions about dosing, imaging studies and other elements of medical management.

For problems associated with postsurgical procedures or an injury, physical therapy can be a reasonable strategy. Working to not lose any function and regain what was lost is important to recovering independence. Routine physical therapy can be helpful in addressing muscle weakness and flexibility; however patients must maintain the exercises regularly even after therapy sessions have completed [86]. Adherence among older adults to exercises recommended by the physical therapists unfortunately tends to be poor [87]. Despite the benefits of physical therapy, only few ever access occupational/physical therapy despite Medicare coverage [88]. Barriers to outpatient physical therapy include poor social support, depression, low activity lifestyle, anxiety, and low self-efficacy [89].

Organized exercise and movement programs are also beneficial in enhancing functional [86]. Tai Chi is effective, when engaged regularly for eight to 12 months [90] in improving strength and endurance [91], as well as balance and flexibility [92]. Yoga is beneficial [93] and many continue to adhere to regular participation [94]. General aerobic exercise is effective in enhancing ambulatory status and gait [95-97].

To reduce the potential for functional status limitations after surgery, adequate nutrition is important for recovery [98]. Body Mass Index (BMI) influences muscle strength, as well as physical function in older people [99] Malnutrition is common in older people and is reflective of poor performance status. Older people with higher BMI tend to have more functional status impairment [100]. Addressing nutrition can help improve functional and physical outcomes [101].

\section{Conclusions}

Functional status assessment and management are critical to the care of the older person. Incorporating functional assessment in ambulatory care facilities can help medical management strategies, coping with disability and patient/family interactions. Many clinical instruments exist that are either self-report or performance based that require brief amounts of time to conduct. Interventions range from treatment of the underlying cause, to physical therapy or participation in regular exercise. Preservation of independence is a critical feature of care for the older person and functional status assessment is part of that effort.

\section{Acknowledgments}

I would like to acknowledge my friends and colleagues at the Stefanie Spielman Comprehensive Cancer Center at the Ohio State University and at the Senior Adult Oncology Program at the H. Lee Moffitt Cancer Center. Years of working with wonderful patients, families and colleagues have offered the experience of understanding functional status in senior adult oncology patients. 


\section{Author Contributions}

The author has contributed $100 \%$ of the effort to write this manuscript.

\section{Conflicts of Interest}

The author declares no conflict of interest.

\section{References}

1. Overcash, J.A.; Beckstead, J. Predicting falls in older patients using components of a comprehensive geriatric assessment. Clin. J. Oncol. Nurs. 2008, 12, 941-949.

2. Kaminska, M.S.; Brodowski, J.; Karakiewicz, B. Fall risk factors in community-dwelling elderly depending on their physical function, cognitive status and symptoms of depression. Int. J. Environ. Res. Public Health 2015, 12, 3406-3416.

3. Partridge, J.S.; Fuller, M.; Harari, D.; Taylor, P.R.; Martin, F.C.; Dhesi, J.K. Frailty and poor functional status are common in arterial vascular surgical patients and affect postoperative outcomes. Int. J. Surg. 2015, 18, 57-63.

4. Whitson, H.E.; Sanders, L.L.; Pieper, C.F.; Morey, M.C.; Oddone, E.Z.; Gold, D.T.; Cohen, H.J. Correlation between symptoms and function in older adults with comorbidity. J. Am. Geriatr. Soc. 2009, 57, 676-682.

5. Garman, K.S.; Cohen, H.J. Functional status and the elderly cancer patient. Crit. Rev. Oncol. Hematol. 2002, 43, 191-208.

6. Chen, H.; Cantor, A.; Meyer, J.; Corcoran, M.B.; Grendys, E.; Cavanaugh, D.; Antonek, S.; Camarata, A.; Haley, W.; Balducci, L.; et al. Can older cancer patients tolerate chemotherapy? A prospective pilot study. Cancer 2003, 97, 1107-1114.

7. Barbaglia, G.; ten Have, M.; van Dorsselaer, S.; Alonso, J.; Vilagut, G.; de Graaf, R. Low functional status as a predictor of incidence of emotional disorders in the general population. Qual. Life Res. 2015, 24, 651-659.

8. Rijk, J.M.; Roos, P.R.; Deckx, L.; van den Akker, M.; Buntinx, F. Prognostic value of handgrip strength in people aged 60 years and older: A systematic review and meta-analysis. Geriatr. Gerontol. Int. 2015, doi:10.1111/ggi.12508.

9. Kutner, N.G.; Zhang, R.; Huang, Y.; Painter, P. Gait speed and mortality, hospitalization, and functional status change among hemodialysis patients: A US renal data system special study. Am. J. Kidney Dis. 2015, 66, 297-304.

10. Zuccolo, P.F.; Avila, R.; Nakano, E.Y.; Litvoc, J.; Lopes, M.A.; Bottino, C.M. Instrumental activities of daily living performance in healthy and cognitively intact seniors from a Brazilian sample and its relation to age and other socio-demographic variables. Int. Psychogeriatr. 2012, 24, 784-793.

11. Stenholm, S.; Westerlund, H.; Salo, P.; Hyde, M.; Pentti, J.; Head, J.; Kivimäki, M.; Vahtera, J. Age-related trajectories of physical functioning in work and retirement: The role of sociodemographic factors, lifestyle and disease. J. Epidemiol. Community Health 2014, 68, 503-509. 
12. O’Connor, T.; Shinde, A.; Doan, C.; Katheria, V.; Hurria A. Managing breast cancer in the older patient. Clin. Adv. Hematol. Oncol. 2013, 11, 341-347.

13. Ervin, R.B. Prevalence of functional limitations among adults 60 years of age and over: United Stated, 1999-2002. Adv. Data Vital Health Stat. 2006, 375, 1-7.

14. Mariano, C.; Williams, G.; Deal, A.; Alston, S.; Bryant, A.L.; Jolly, T.; Muss, H.B. Geriatric assessment of older adults with cancer during unplanned hospitalizations: An opportunity in disguise. Oncologist 2015, 20, 767-772.

15. Calkins, D.R.; Rubenstein, L.V.; Cleary, P.D.; Davies, A.R.; Jette, A.M.; Fink, A.; Kosecoff, J.; Young, R.T.; Brook, R.H.; Delbanco, T.L. Failure of physicians to recognize functional disability in ambulatory patients. Ann. Intern. Med. 1991, 114, 451-454.

16. Abdulaziz, K.; Brehaut, J.; Taljaard, M.; Émond, M.; Sirois, M.J.; Lee, J.S.; Wilding, L.; Perry, J.J. National survey of emergency physicians to define functional decline in elderly patients with minor trauma. CJEM 2015, 11, 1-9.

17. Overcash, J. Prediction of falls in older adults with cancer: A preliminary study. Oncol. Nurs. Forum. 2007, 34, 341-346.

18. Klepin, H.D.; Geiger, A.M.; Tooze, J.A.; Kritchevsky, S.B.; Williamson, J.D.; Ellis, L.R.; Levitan, D.; Pardee, T.S.; Isom, S.; Powell, B.L. The feasibility of inpatient geriatric assessment for older adults receiving induction chemotherapy for acute myelogenous leukemia. J. Am. Geriatr. Soc. 2011, 59, 1837-1846.

19. Avelino-Silva, T.J.; Farfel, J.M.; Curiati, J.A.; Amaral, J.R.; Campora, F.; Jacob-Filho, W. Comprehensive geriatric assessment predicts mortality and adverse outcomes in hospitalized older adults. BMC Geriatr. 2014, doi:10.1186/1471-2318-14-129.

20. Gerrard, P.; Luce, J.; Bean, J.F.; Jette, A.M.; Zafonte, R. Benchmarking functional status in older adults. Arch. Phys. Med. Rehabil. 2014, 95, 2264-2271.

21. Kresevic, D. Nursing standard of practice protocol: Assessment of physical function. Evid. Based Geriatr. Top. 2012, 24, 250-276.

22. American Geriatrics Society (AGS). Clinical Guideline: Comprehensive Geriatric Assessment; AGS Public Policy Committee: New York, NY, USA, 2005.

23. Katz, S.; Downs, T.D.; Cash, H.R.; Grotz, R.C. Progress in development of the index of ADL. Gerontologist 1970, 10, 20-30.

24. Lawton, M.; Brody, E.M. Assessment of older people: Self-maintaining and instrumental activities of daily living. Gerontologist 1969, 9, 179-186.

25. Fong, T.G.; Gleason, L.J.; Wong, B.; Jones, R.N.; Schmitt, E.M.; de Rooij, S.E.; Saczynski, J.S.; Gross, A.L.; Bean, J.F.; Brown, C.J.; et al. Cognitive and physical demands of activities of daily living in older adults: Validation of expert panel ratings. J. Inj. Funct. Rehabil. 2015, 7, 727-735.

26. Goodwin, J.S.; Hunt, W.C.; Samet, J.M. Determinants of cancer therapy in elderly patients. Cancer 1993, 72, 594-601.

27. Ostensson, E.; Alder, S.; Elfstrom, K.M.; Sundström, K.; Zethraeus, N.; Arbyn, M.; Andersson, S. Barriers to and facilitators of compliance with clinic-based cervical cancer screening: Population-based cohort study of women aged 23-60 years. PLOS ONE 2015, 10, e0128270. 
28. Berg, C.J.; Stratton, E.; Esiashvili, N.; Mertens A. Young adult cancer survivors' experience with cancer treatment and follow-up care and perceptions of barriers to engaging in recommended care. J. Cancer Educ. 2015, doi:10.1007/s13187-015-0853-9.

29. Scott, A.R.; Rush, A.J., III; Naik, A.D.; Berger, D.H.; Suliburk, J.W. Surgical follow-up costs disproportionately impact low-income patients. J. Surg. Res. 2015, doi:10.1016/j.jss.2015.04.013.

30. Sercekus, P.; Besen, D.B.; Gunusen, N.P.; Edeer, A.D. Experiences of family caregivers of cancer patients receiving chemotherapy. Asian Pac. J. Cancer Prev. 2014, 15, 5063-5069.

31. MacLeod, K.E.; Satariano, W.A.; Ragland, D.R. The impact of health problems on driving status among older adults. J. Transp. Health 2014, 1, 86-94.

32. Stevens, J.A.; Haas, E.N.; Haileyesus, T. Nonfatal bathroom injuries among persons aged $\geq 15$ years-United States, 2008. J. Saf. Res. 2011, 42, 311-315.

33. Fong, J.H.; Mitchell, O.S.; Koh, B.S. Disaggregating activities of daily living limitations for predicting nursing home admission. Health Serv. Res. 2015, 50, 560-578.

34. Bendixen, H.J.; Waehrens, E.E.; Wilcke, J.T.; Sorensen, L.V. Self-reported quality of ADL task performance among patients with COPD exacerbations. Scand. J. Occup. Ther. 2014, 21, 313-320.

35. Omli, R.; Hunskaar, S.; Mykletun, A.; Romild, U.; Kuhry E. Urinary incontinence and risk of functional decline in older women: Data from the Norwegian HUNT-study. BMC Geriatr. 2013, doi:10.1186/1471-2318-13-47.

36. Abreu, H.C.; Reiners, A.A.; Azevedo, R.C.; Silva, A.M.; Abreu, D.R.; Oliveira, A.D. Incidence and predicting factors of falls of older inpatients. Rev. Saude Publica 2015, 49, 13-20.

37. Maxwell, C.J.; Soo, A.; Hogan, D.B.; Wodchis, W.P.; Gilbart, E.; Amuah, J.; Eliasziw, M.; Hagen, B.; Strain, L.A. Predictors of nursing home placement from assisted living settings in Canada. Can. J. Aging 2013, 32, 333-348.

38. Tariq, S.H.; Wilson, M.M. Geriatric incontinence-Selected questions. Mo. Med. 2007, 104, $440-445$.

39. Gorina, Y.; Schappert, S.; Bercovitz, A.; Elgaddal, N.; Kramarow, E. Prevalance of incontience among older Americans. Vital Health Stat. 2014, 36, 1-33.

40. Mira, J.J.; Lorenzo, S.; Guilabert, M.; Navarro, I.; Perez-Jover, V. A systematic review of patient medication error on self-administering medication at home. Expert Opin. Drug Saf. 2015, 14, $815-838$.

41. Field, T.S.; Mazor, K.M.; Briesacher, B.; Debellis, K.R.; Gurwitz, J.H. Adverse drug events resulting from patient errors in older adults. J. Am. Geriatr. Soc. 2007, 55, 271-276.

42. Field, T.S.; Gurwitz, J.H.; Harrold, L.R.; Rothschild, J.; DeBellis, K.R.; Seger, A.C.; Auger, J.C.; Garber, L.A.; Cadoret, C.; Fish, L.S.; et al. Risk factors for adverse drug events among older adults in the ambulatory setting. J. Am. Geriatr. Soc. 2004, 52, 1349-1354.

43. Hsu, J.W.; Willis, R. Dementia risk and financial decision making by older households: The impact of information. J. Hum. Cap. 2013, doi:10.1086/674105.

44. Shin, J.H.; Lim, J.Y.; Kim, K.W.; Kim, S.; Lee, J.; Paik, N.J. Functional and physical abilities in the early continuum of cognitive decline. Dement. Geriatr. Cognit. Disord. 2015, 39, 41-51.

45. Pew Research Center. Older Adults and Technology Use: 2014. Available online: http://www.pewinternet.org/2014/04/03/older-adults-and-technology-use/ (accessed on 2 March 2015). 
46. Crawford, R.S.; Cambria, R.P.; Abularrage, C.J.; Conrad, M.F.; Lancaster, R.T.; Watkins, M.T.; LaMuraglia, G.M. Preoperative functional status predicts perioperative outcomes after infrainguinal bypass surgery. J. Vasc. Surg. 2010, doi:10.1016/j.jvs.2009.08.065.

47. Scarborough, J.E.; Bennett, K.M.; Englum, B.R.; Pappas, T.N.; Lagoo-Deenadayalan, S.A. The impact of functional dependency on outcomes after complex general and vascular surgery. Ann. Surg. 2015, 261, 432-437.

48. Hoyer, E.H.; Needham, D.M.; Miller, J.; Deutschendorf, A.; Friedman, M.; Brotman, D.J. Functional status impairment is associated with unplanned readmissions. Arch. Phys. Med. Rehabil. 2013, 94, 1951-1958.

49. Hurria, A. Chemotherapy and toxicity assessment. J. Geriatr. Oncol. 2014, doi:http://dx.doi.org/ 10.1016/j.jgo.2014.06.008.

50. Abete, P.; Cherubini, A.; di Bari, M.; Vigorito, C.; Viviani, G.; Marchionni, N.; D’Ambrosio, D.; Golino, A.; Serra, R.; Zampi, E.; et al. Does comprehensive geriatric assessment improve the estimate of surgical risk in elderly patients? An Italian multicenter observational study. Am. J. Surg. 2015, doi:10.1016/j.amjsurg.2015.04.016.

51. Ferrat, E.; Paillaud, E.; Laurent, M.; le Thuaut, A.; Caillet, P.; Tournigand, C.; Lagrange, J.L.; Canouï-Poitrine, F.; Bastuji-Garin, S.; ELPACA Study Group. Predictors of 1-year mortality in a prospective cohort of elderly patients with cancer. J. Gerontol. Ser. A 2015, 70, 1148-1155.

52. Caillet, P.; Canoui-Poitrine, F.; Vouriot, J.; Berle, M.; Reinald, N.; Krypciak, S.; Bastuji-Garin, S.; Culine, S.; Paillaud, E. Comprehensive geriatric assessment in the decision-making process in elderly patients with cancer: ELCAPA study. J. Clin. Oncol. 2011, 29, 3636-3642.

53. Ailshire, J.A.; Beltran-Sanchez, H.; Crimmins, E.M. Becoming centenarians: Disease and functioning trajectories of older US Adults as they survive to 100. J. Gerontol. Ser. A 2015, 70, 193-201.

54. National Council on Aging. The United Stated of Aging Survey Results 2014. Available online: http://www.ncoa.org/improve-health/community-education/united-states-of-aging/2014/usasurvey-results-2014.html (accessed on 20 June 2015).

55. Federal Interagency Forum on Aging-Related Statistics (Forum). Older Americans 2012: Key Indicators of Well-Being. 2012. Available online: http:/www.agingstats.gov/agingstatsdotnet/ Main_Site/Data/2012_Documents/Docs/EntireChartbook.pdf (accessed on 20 June 2015).

56. Cella, D.F.; Tulsky, D.S.; Gray, G.; Sarafian, B.; Linn, E.; Bonomi, A.; Silberman, M.; Yellen, S.B.; Winicour, P.; Brannon, J.; et al. The functional assessment of cancer therapy scale: Development and validation of the general measure. J. Clin. Oncol. 1993, 11, 570-579.

57. Winstead-Fry, P.; Schultz, A. Psychometric analysis of the Functional Assessment of Cancer Therapy-General (FACT-G) scale in a rural sample. Cancer 1997, 79, 2446-2452.

58. Overcash, J.; Extermann, M.; Parr, J.; Perry, J.; Balducci, L. Validity and reliability of the FACT-G scale for use in the older person with cancer. Am. J. Clin. Oncol. 2001, 24, 591-596.

59. Ware, J.E., Jr.; Sherbourne, C.D. The MOS 36-item short-form health survey (SF-36). I. Conceptual framework and item selection. Med. Care 1992, 30, 473-483.

60. Wade, D.T.; Collin, C. The Barthel ADL Index: A standard measure of physical disability? Int. Disabil. Stud. 1988, 10, 64-67. 
61. Shah, S.; Vanclay, F.; Cooper B. Improving the sensitivity of the Barthel Index for stroke rehabilitation. J. Clin. Epidemiol. 1989, 42, 703-709.

62. Pfeiffer, E. A short portable mental status questionnaire for the assessment of organic brain deficit in elderly patients. J. Am. Geriatr. Soc. 1975, 23, 433-441.

63. Lawton, M.P.; Moss, M.; Fulcomer, M.; Kleban, M.H. A research and service oriented multilevel assessment instrument. J. Gerontol. 1982, 37, 91-99.

64. Verfasser, U. Guideline for the prevention of falls in older persons. American Geriatrics Society, British Geriatrics Society, and American Academy of Orthopaedic Surgeons Panel on Falls Prevention. J. Am. Geriatr. Soc. 2001, 49, 664-672.

65. Podsiadlo, D.; Richardson, S. The timed "Up \& Go": A test of basic functional mobility for frail elderly persons. J. Am. Geriatr. Soc. 1991, 39, 142-148.

66. Shumway-Cook, A.; Brauer, S.; Woollacott, M. Predicting the probability for falls in community-dwelling older adults using the Timed Up \& Go Test. Phys. Ther. 2000, 80, 896-903.

67. Beseler, M.R.; Rubio, C.; Duarte, E.; Hervás, D.; Guevara, M.C.; Giner-Pascual, M.; Viosca, E. Clinical effectiveness of grip strength in predicting ambulation of elderly inpatients. Clin. Interv. Aging 2014, 9, 1873-1877.

68. Kim, Y.H.; Kim, K.I.; Paik, N.J.; Kim, K.W.; Jang, H.C.; Lim, J.Y. Muscle strength: A better index of low physical performance than muscle mass in older adults. Geriatr. Gerontol. Int. 2015, doi:10.1111/ggi.12514.

69. Karpman, C.; Benzo, R. Gait speed as a measure of functional status in COPD patients. Int. J. Chronic Obstruct. Pulmonary Dis. 2014, 9, 1315-1320.

70. Middleton, A.; Fritz, S.L.; Lusardi, M. Walking speed: The functional vital sign. J. Aging Phys. Act. 2015, 23, 314-322.

71. Fritz, S.; Lusardi, M. White paper: "Walking speed: The sixth vital sign”. J. Geriatr. Phys. Ther. 2009, 32, 46-49.

72. Studenski, S.; Perera, S.; Wallace, D.; Chandler, J.M.; Duncan, P.W.; Rooney, E.; Fox, M.; Guralnik, J.M. Physical performance measures in the clinical setting. J. Am. Geriatr. Soc. 2003, 51, 314-322.

73. Miyamoto, S.; Nagaya, N.; Satoh, T.; Kyotani, S.; Sakamaki, F.; Fujita, M.; Nakanishi, N.; Miyatake, K. Clinical correlates and prognostic significance of six-minute walk test in patients with primary pulmonary hypertension. Comparison with cardiopulmonary exercise testing. Am. J. Respir. Crit. Care Med. 2000, 161, 487-492.

74. Opasich, C.; Pinna, G.D.; Mazza, A.; Febo, O.; Riccardi, R.; Riccardi, P.G.; Capomolla, S.; Forni, G.; Cobelli, F.; Tavazzi, L. Six-minute walking performance in patients with moderate-to-severe heart failure; is it a useful indicator in clinical practice? Eur. Heart J. 2001, 22, 488-496.

75. Gill, T.M. Disentangling the disabling process: Insights from the precipitating events project. Gerontologist 2014, 54, 533-549.

76. Balducci, L. Frailty: A common pathway in aging and cancer. Interdiscipl. Top. Gerontol. 2013, $38,61-72$.

77. Song, H.J.; Meade, K.; Akobundu, U.; Sahyoun, N.R. Depression as a correlate of functional status of community-dwelling older adults: Utilizing a short-version of 5-item Geriatric Depression Scale as a screening tool. J. Nutr. Health Aging 2014, 18, 765-770. 
78. Hybels, C.F.; Pieper, C.F.; Blazer, D.G. The complex relationship between depressive symptoms and functional limitations in community-dwelling older adults: The impact of subthreshold depression. Psychol. Med. 2009, 39, 1677-1688.

79. Nyunt, M.S.; Lim, M.L.; Yap, K.B.; Ng, T.P. Changes in depressive symptoms and functional disability among community-dwelling depressive older adults. Int. Psychogeriatr. 2012, 24, 1633-1641.

80. Chen, C.C.; Wang, C.; Huang, G.H. Functional trajectory 6 months posthospitalization: A cohort study of older hospitalized patients in Taiwan. Nurs. Res. 2008, 57, 93-100.

81. Gill, T.M.; Allore, H.G.; Gahbauer, E.A.; Han, L. Establishing a hierarchy for the two components of restricted activity. J. Gerontol. Ser. A 2015, 70, 892-898.

82. Graf, C. Functional decline in hospitalized older adults. Am. J. Nurs. 2006, 106, 58-68.

83. Boltz, M.; Capezuti, E.; Shabbat, N. Nursing staff perceptions of physical function in hospitalized older adults. Appl. Nurs. Res. 2011, 24, 215-222.

84. Boltz, M.; Resnick, B.; Capezuti, E.; Shuluk, J.; Secic, M. Functional decline in hospitalized older adults: Can nursing make a difference? Geriatr. Nurs. 2012, 33, 272-279.

85. Corsonello, A.; Pedone, C.; Lattanzio, F.; Lucchetti, M.; Garasto, S.; di Muzio, M.; Giunta, S.; Onder, G.; di Iorio, A.; Volpato, S.; et al. Potentially inappropriate medications and functional decline in elderly hospitalized patients. J. Am. Geriatr. Soc. 2009, 57, 1007-1014.

86. Cesari, M.; Vellas, B.; Hsu, F.C.; Newman, A.B.; Doss, H.; King, A.C.; Manini, T.M.; Church, T.; Gill, T.M.; Miller, M.E.; et al. A physical activity intervention to treat the frailty syndrome in older persons-results from the LIFE-P study. J. Gerontol. Ser. A 2015, 70, 216-222.

87. Forkan, R.; Pumper, B.; Smyth, N.; Wirkkala, H.; Ciol, M.A.; Shumway-Cook, A. Exercise adherence following physical therapy intervention in older adults with impaired balance. Phys. Ther. 2006, 86, 401-410.

88. Pergolotti, M.; Deal, A.M.; Lavery, J.; Reeve, B.B.; Muss, H.B. The prevalence of potentially modifiable functional deficits and the subsequent use of occupational and physical therapy by older adults with cancer. J. Geriatr. Oncol. 2015, 6, 194-201.

89. Jack, K.; McLean, S.M.; Moffett, J.K.; Gardiner, E. Barriers to treatment adherence in physiotherapy outpatient clinics: A systematic review. Man. Ther. 2010, 15, 220-228.

90. Song, Q.H.; Shen, G.Q.; Xu, R.M.; Zhang, Q.H.; Ma, M.; Guo, Y.H.; Zhao, X.P.; Han, Y.B. Effect of Tai Chi exercise on the physical and mental health of the elder patients suffered from anxiety disorder. Int. J. Physiol. Pathophysiol. Pharmacol. 2014, 6, 55-60.

91. Kim, T.H.; Eke Dogra, S.; Al-Sahab, B.; Tamim, H. Comparison of functional fitness outcomes in experienced and inexperienced older adults after 16-week tai chi program. Altern. Ther. Health Med. 2014, 20, 20-25.

92. Taylor-Piliae, R.E.; Haskell, W.L.; Stotts, N.A.; Froelicher, E.S. Improvement in balance, strength, and flexibility after 12 weeks of Tai chi exercise in ethnic Chinese adults with cardiovascular disease risk factors. Altern. Ther. Health Med. 2006, 12, 50-58.

93. Cheung, C.; Wyman, J.F.; Resnick, B.; Savik, K. Yoga for managing knee osteoarthritis in older women: A pilot randomized controlled trial. BMC Complement. Altern. Med. 2014, doi:10.1186/ 1472-6882-14-160. 
94. Cheung, C.; Justice, C.; Peden-McAlpine, C. Yoga adherence in older women six months post-osteoarthritis intervention. Glob. Adv. Health Med. 2015, 4, 16-23.

95. Wang, R.Y.; Wang, Y.L.; Cheng, F.Y.; Chao, Y.H.; Chen, C.L.; Yang, Y.R. Effects of combined exercise on gait variability in community-dwelling older adults. Age 2015, doi:10.1007/s11357015-9780-2.

96. Cao, Z.B.; Maeda, A.; Shima, N.; Kurata, H.; Nishizono, H. The effect of a 12-week combined exercise intervention program on physical performance and gait kinematics in community-dwelling elderly women. J. Physiol. Anthropol. 2007, 26, 325-332.

97. Chandler, J.M.; Duncan, P.W.; Kochersberger, G.; Studenski, S. Is lower extremity strength gain associated with improvement in physical performance and disability in frail, community-dwelling elders? Arch. Phys. Med. Rehabil. 1998, 79, 24-30.

98. Goisser, S.; Schrader, E.; Singler, K.; Ertsch, T.; Gefeller, O.; Biber, R.; Bail, H.J.; Sieber, C.C.; Volkert, D. Low postoperative dietary intake is associated with worse functional course in geriatric patients up to 6 months after hip fracture. Br. J. Nutr. 2015, 20, 1-11.

99. Minematsu, A.; Hazaki, K.; Harano, A.; Okamoto, N.; Kurumatani, N. Differences in physical function by body mass index in elderly Japanese individuals: The Fujiwara-kyo Study. Obes. Res. Clin. Pract. 2015, doi:10.1016/j.orcp.2015.05.009.

100. Bahat, G.; Tufan, A.; Aydin, Y.; Tufan, F.; Bahat, Z.; Akpinar, T.S.; Soyluk, O.; Erten, N.; Karan, M.A. The relationship of body mass index and the functional status of community-dwelling female older people admitting to a geriatric outpatient clinic. Aging Clin. Exp. Res. 2015, 27, 303-308.

101. Chevalier, S.; Saoud, F.; Gray-Donald, K.; Morais, J.A. The physical functional capacity of frail elderly persons undergoing ambulatory rehabilitation is related to their nutritional status. J. Nutr. Health Aging 2008, 12, 721-726.

(C) 2015 by the authors; licensee MDPI, Basel, Switzerland. This article is an open access article distributed under the terms and conditions of the Creative Commons Attribution license (http://creativecommons.org/licenses/by/4.0/). 